\title{
HISTÓRIA do \\ DIREITO
}

'Moderno' y 'posmoderno' en la historia del derecho en Italia

'Moderno' e 'Pós-moderno' na história do direito na Itália

'Modern' and 'post-modern' in italian legal history

Paolo Grossi ${ }^{1}$ 


\title{
RESUMO
}

0 presente texto trata-se do discurso proferido em razão da conferência inaugural do primeiro Congresso da Sociedade Espanhola de História do Direito. Seu objetivo é contextualizar e caracterizar os dois momentos distintos de florescimento jurídico na península italiana, a saber: a modernidade herdada da Revolução Francesa e a pós-modernidade do entreguerras. Para tanto, aborda essa modernidade jurídica italiana como o império do estatismo e do legalismo, período em que a burguesia pretendia controlar toda realidade social por meio do monopólio da produção jurídica e seu consequente afastamento do povo, isto é, uma busca por um Direito codificado abstrato e pretensamente claro, coerente e seguro. Em seguida, em contraste com esse absolutismo jurídico, surge o Direito pós-moderno italiano, nascente durante a 1aㅡ Guerra Mundial e concretizado na Constituição pós-guerra de 1948, cujas peculiaridades são suas facticidade e pluralidade, ou seja, é uma arte jurídica espontânea que germina e autoorganiza-se a partir da própria sociedade em que está inserida, culminando com os direitos sociais. 0 discurso conclui que os direitos pós-modernos têm, cada vez mais, tornando-se valores inderrogáveis e fundamentais tanto da República quando do Estado italiano.

Palavras-chave: Modernidade jurídica, pós-modernidade jurídica, absolutismo jurídico, legalismo, estatismo, monismo, codificação, pluralidade jurídica, facticidade, direitos sociais, constituição italiana.

\begin{abstract}
The present text is the speech given due to the inaugural conference of the first Congress of the Spanish Society of the History of Law. Its objective is to contextualize and characterize the two distinct moments of legal development in the Italian peninsula, namely the modernity inherited from the French Revolution and the post-modernity of the interwar period. For such, it addresses the Italian legal modernity as the rule of statism and legalism, a moment in which the bourgeoisie intended to control all social reality through the monopoly of legal production and its separation from the people, i.e., a search for a codified and abstract law, supposedly clear, coherent and secure. Then, in contrast to this legal absolutism, Italian postmodern law emerged, born during the First World War and materialized in the postwar Constitution of 1948, whose peculiarities are its facticity and plurality, i.e., a spontaneous law which germinates and organizes itself from the very society in which it is inserted, culminating in the promulgation of social rights. The speech concludes that postmodern rights have, increasingly, become fundamental values of both the Italian Republic and State.
\end{abstract}

Keywords: legal modernity, legal postmodernity, legal absolutism, legalism, statism, monism, codification, legal plurality, facticity, social rights, Italian constitution. 
Quiero agradecer, de todo corazón, al Presidente Bermejo Castrillo el honor que me concede al invitarme a pronunciar la "conferencia inaugural" del primer Congreso de la "Sociedad Española de Historia del Derecho". El tema, que he elegido, dedicado al desarrollo del derecho en Italia en los últimos dos siglos, puede interesar a los Colegas españoles precisamente porque Italia y España, aun perteneciendo ambas al universo del 'Civil Law', han tenido una historia juridica bastante distinta. La "conferencia" puede, por tanto, ofrecer un provechoso instrumento de comparación.

1. Desde hace varios años vengo hablando y escribiendo de "moderno" y "posmoderno"; oficialmente al menos desde 2010 cuando, invitado a pronunciar el 'discorso inaugurale' del año academico de la Università di Ferrara, lo quise intitular "Novecientos juridico: un siglo posmoderno".

Utilizando estas dos calificaciones, no pretendía delinear categorías históricas generales, sino más bien dotarme de un valido instrumento ordenador para encuadrar eficazmente el desarrollo del derecho en Italia. Eficaz porque la historia juridica italiana, a lo largo de los dos siglos que nos preceden, aparece caracterizada por una profunda discontinuidad: dos momentos sucesivos intensamente diferenciados, cada uno de los cuales es portador de un mensaje absolutamente específico y peculiar.

2. Lo "moderno" tiene su fase culminante al final del Setecientos, cuando la revolución francesa cataliza las exigencias de la ilustración europea continental y las traduce en la estructura de un Estado nuevo, el elaborado en el laboratorio jacobino. Es un Estado fuerte, que se ha liberado del pluralismo jurídico del antiguo régimen, un Estado compacto y centralizado, ajeno ya a la "societé de societés" de la vieja monarquía borbónica. Más bien, exactamente lo contrario, ya que quiere monopolizar la producción del derecho y efectuar así el ineludible control de toda dimensión social y, así, también de la dimensión jurídica.

La burguesia, que - con la revolución- conquistó en Francia el poder político, considera el derecho una argamasa muy relevante para el pleno dominio de la sociedad; todo el derecho, comenzando por el derecho privado, que se ocupa de institutos basilares para una civilización burguesa, como propriedad, contrato, sucesión mortis causa. És una estrategia que encuentra su confirmación y también su pleno desarrollo con la codificación general; desde 1791 se aspira a un 'Codigo Civil', y entre los afios 1804 y 1810, con el déspota Napoleón, asistimos a una extraordinaria obra codificadora que afronta las grandes areas del orden jurídico (civil, mercantil, penal, procesal).

Aquí esta lo "nuevo" que típica lo "moderno" y lo diferencia del antiguo regimen: la estrecha —incluso, necesaria - vinculación del derecho al poder politico, y la consecuente identificación de su manifestación con la voluntad del poder supremo, es decir con la ley. Entonces, rígido estatalismo y rígido legalismo son los indicadores de la modernidad jurídica; que produce algunos frutos indudables respecto al caótico orden jurídico prerevolucionario: claridad, certeza, capacidad de reducirse a un sistema de extraordinaria coherencia.

He usado, a propósito, el verbo reducirse, y sucede precisamente así. El pluralismo de las fuentes del derecho, que había caracterizado el antiguo derecho romano, el ius commune medieval y posmedieval, sufre una dramática reducción. El derecho es generado (o mejor, es creado) en los nobles palacios del poder, desde los cuales se proyecta hacia la base social concebida como pasiva e inerte, a la que se le pide obediencia. Es una concepción elitista, que tiene su origen primero en los círculos ilustrados parisinos de mitad del Setecientos, con un resultado 
dañino, tanto para la sociedad, como para el derecho. Se separa, cada vez más, poder politico y sociedad, así como la sociedad del derecho, ahora reducido a voz del poder. Otro resultado para el derecho es que, concebido como producto de una voluntad suprema, tiende a no mezclarse con los hechos vivos de la existencia cotidiana de los ciudadanos y a proponerse como osamenta formal absolutamente abstracta, dentro de la cual los hechos están aprisionados a la fuerza'.

Ya que hablo a los Colegas españoles historiadores del derecho, puedo prever una exigencia de mayor precisión en relación con la situation politica de los Estados, que compartimentan la península italiana en la primera mitad del Ochocientos y que se relacionan más con Viena que con Paris. Es fácil responder que la influencia de la revolución francesa y de la gran codificación napoleónica es generalmente bastante intensa no solo sobre nuestra ciencia jurídica, sino además sobre las operaciones codificadoras de la península, que se inspiran en el modelo francés y no en el del Imperio austriaco (esto no solo en la primera codificación unitaria del Reino de Italia nacido en 1861, sino también en los numerosos Códigos del precedente momento de la restauración tras el Congreso vienense de 1815). Dos son las explicaciones posibles: este modelo estuvo vigente en Italia durante la dominación franco-napoleónica; se considera que este modelo tutela validamente los intereses de la clase burguesa que se está haciendo fuerte también en Italia.

Entonces, repitámoslo: modernidad jurídica quiere decir estatalismo y legalismo; es decir monismo jurídico, con el Estado como única fuente de producción del derecho; con una rígida jerarquización de las fuentes y con la reducción a un rango absolutamente marginal de la costumbre, de la jurisprudencia practica, de la ciencia jurídica. Es el tiempo de lo que llamo absolutismo jurídico.

3. Es un tiempo que se extiende, en Italia, hasta la conclusión del siglo XIX, es decir mientras la plataforma social permanece en su estática inercia, y el paisaje jurídico se mantiene sin complicaciones dominado por dos sujetos fuertes, el Estado pensado como macro-individuo y el singular micro-individuo (este segundo es tornado en consideración, en la imperativa civilización burguesa, únicamente al completarse por una conspicua integración económica). Tal paisaje viene turbado cuando los estratos bajos de la sociedad adquieren una inedita conciencia, al redescubrir las formaciones colectivas, que la revolución francesa había suprimido para garantizar la cohesión (aunque solo aparente) y que resultan el salvamiento para la clase de los no pudientes sociológicamente extraños al proyecto revolucionario de 1789 . Y tienen, en los últimos decenios del Ochocientos, un florecer de organizaciones colectivas bastante diversificadas en sus especificas finalidades (religiosas, sindicales, politicas, profesionales, asistenciales, cooperativas) pero unificadas por una común finalidad: hacer más capaz al sujeto desposeído, debilísimo mientras permanece individuo aislado. Si se quiere, es un formidable despertar, al que se enfrente la reaction violenta del poder burgués; y a huelgas y revueltas populares se reacciona con represiones incluso sangrientas.

En esas turbulencias, que el Estado consigue momentáneamente reprimir pero no extinguir, esta el comienzo de un tiempo nuevo en Italia, un tiempo posmoderno, que vemos nítidamente consolidarse en el siglo nuevo, el Novecientos. Cuando, durante mis cuarenta años de docencia en mi amada Universidad de Florencia, quería, sucintamente pero de manera realista, expresar a los estudiantes el sentido del desarrollo del derecho decimonónico, lo condesaba en esta frase eficaz: siempre más sociedad, siempre menos Estado. Y era una referencia, quizás demasiado sucinta pero puntual. Era, en efecto, la sociedad civil que retomaba lentamente su protagonismo. Entre los juristas italianos capta con gran lucidez este movimiento uno de los 
más inteligentes cultivadores del derecho publico, Santi Romano, que, en un famoso discurso inaugural para el año académico de la antigua Universidad de Pisa, en 1909, que quiso intitular "Lo Stato moderno e la sua crisi" [El Estado moderno y su crisis], identifico el comienzo de esta 'crisis' precisamente en la autoorganización y dinamización de la sociedad italiana, que por entonces se acentuaba. El trazo más vistoso nos lo ofrece el plano constitucional, con la transformación de la democracia burguesa (incompleta, ya que ligaba —en las elecciones politicasla titularidad del voto a la titularidad de una cierta ganancia económica) en una democracia verdaderamente plural, es decir con la llamada al voto de todos los electores masculinos, ricos y pobres, realizada por el Parlamento solo en 1913.

Sobre el plano más propiamente historico-jurídico encontramos otro trazo en un evento que es, por si, únicamente politico: la participación del Reino de Italia en la primera guerra mundial en 1915, que fue ocasión para el florecimiento de una importante legislación excepcional de guerra. Exigida por las enormes necesidades económicas y sociales, tiene una gran relevancia histórica, porque contraviene al carácter tipico de las leyes en el Estado de derecho, es decir la generalidad y la abstracción. Se trataba de una legislación excepcional y, ciertamente, el excepcional estado de guerra estimuló la innovadora manifestación en el plano oficial. Sin embargo, ya en el periodo prebélico, había madurado —en nuestra ciencia jurídica más sensible y culta, dentro de estímulos culturales y técnicas procedentes del área austro-alemana - un alejamiento de la visión del derecho civil como ciencia pura, junto a la exigencia de enfrentar las formas jurídicas a la realidad magmática de los hechos sociales y económicos; y es en este preciso momento - anteguerra, guerra, posguerra - que se rompe la unitariedad de un derecho civil abstracto (el de los Pandectistas alemanes, por ejemplo con su oprimente Isolierung), permitiendo la emersión formal de derechos sectoriales preñados de factualidad económica y social, el 'derecho del trabajo' y el 'derecho agrario'.

4. En aquel 1918 — año de conclusión del conflicto mundial- encontramos en Italia algo más: uno de los más agudos filosofos italianos del derecho, Giuseppe Capograssi, escribió un "Saggio sullo Stato" [Ensayo sobre el Estado] donde considera deberlo describir como un pobre gigante descoronado' no solo también el iuspublicista Santi Romano, mas arriba recordado, que había creído, en 1909 delinear el diagnóstico efectivo de la crisis en acto en las viejas estructuras de impronta ilustrado-jacobina, escribe un opúsculo, exiguo en paginas pero no en contenido, intitulado "L’ordinamento giuridico" [El ordenamiento jurídico] donde se realiza una completa transformación de la visión del derecho: a los ojos nuevos de Romano, el derecho aunque comúnmente aparece en la vida social como mandato, como norma- es en su esencia un ordenamiento de la sociedad, función que puede cumplir únicamente si tiene en cuenta los valores y los intereses difundidos y compartidos en los extractos profundos, en las raíces de la sociedad.

Para Romano el derecho no nace arriba, no es un acto de imperio, una voluntad suprema, más bien es la misma sociedad que se autoordena, respetando y registrando cuanto se origina y se consolida en su constitución más profunda. Es el momento de revancha de la factualidad: los hechos - estructurales, sociales, económicos - necesitados hasta ayer de la obra milagrosa del legislador para pasar de la irrelevancia a la relevancia jurídica, hoy se proponen cada vez más como protagonistas. Varias veces, recientemente, no he dudado en calificar a Santi Romano como un jurista posmoderno y en reconocer en su opúsculo de 1918 el genuino manifiesto de una ciencia jurídica posmoderna. 
5. Sin embargo, si hay un evento que defina la historia jurídica del Novecientos en Italia, este es, sin duda, la 'Constitución' redactada por una ‘Asamblea Constituyente' y entrada en vigor el 1 de enero de 1948. Tras los oprimentes arios de la dictadura fascista (1922-1943), tras la trágicamente loca aventura de la participación italiana en la segunda guerra mundial (19401945), siguió en mi país un momento difícil (entre 1943 y 1947) por las enormes destrucciones que teníamos a las espaldas. Fueron, sin embargo, los primeros arios de una verdadera democracia plural, colmados de esperanzas y de coraje, dirigidos intrépidamente hacia el futuro con la firme convicción de construir un verdadero Estado social de derecho, exactamente lo opuesto a un Estado totalitario pero también muy distinto del Estado burgués pré-fascista.

Lo que me urge subrayar aquí, para los fines de la presente 'conferencia inaugural', es que la novísima Constitución italiana no es el último eslabón de una cadena que une en perfecta continuidad a las 'cartas de los derechos' del constitucionalismo burgués (el francés de finales del Setecientos, por ejemplo), sino que ella está, respecto a él, relación de neta discontinuidad. Estamos, de hecho, frente a una Constitución posmoderna; que no quiere concretarse en 'Déclarations', es decir en vaporosas afirmaciones de indole prevalentemente filosofica; que quiere, por el contrario, delinear el breviario jurídico que actúe de protección para todo ciudadano, rico o pobre, sabio o ignorante.

Los 'Patres' sedentes de la Asamblea Constituyente quisieron leer libremente en las raíces de la comunidad popular italiana, identificar en los estratos profundos valores e intereses compartidos, registrarlos y traducirlos en principios validos como fundamento de derechos esenciales para la vida del ciudadano. De esa manera, se situaron en ideal prosecución de la innovadora Constitución de la república de Weimar, colocándose por ello mismo en un paisaje jurídico que puede calificarse de posmoderno. Un paisaje donde el derecho esta en necesaria conexión no con 'el poder' sino con la 'sociedad'; donde el derecho representa el libre y espontaneo autoordenarse de la sociedad; la cual proyecta sobre el ordenamiento jurídico formal su complejidad social que se hace necesariarmente complejidad jurídica.

Al contrario del derecho de la moderna civilización burguesa, que tenía una estructura bastante simple identificándose en la voz autoritaria del aparato estatal de poderes, es decir en leyes y en la ley/madre que es el Código, al contrario de esta simplicidad, que consistía sin embargo en un sofocante reduccionismo al fin de consentir a los politicos el control de la dimensión jurídica, el rostro del nuevo derecho posmoderno, documentado eficazmente en el mensaje supremo de la Constitución italiana, es complejo como es compleja la existencia cotidiana del ciudadano. No se trata aquí de vaporosas declaraciones filosófico-politicas, sino de principios funcionales a la tutela jurídica de esa existencia, tan ciertos que, mientras en las 'cartas de los derechos' dieciochescas se hablaba abstractamente de derechos fundamentales, aquí se habla claramente y concretamente de salud, de trabajo, de economía, de escuela, de educación, es decir de hechos de la vida. Se trata de principios que son ab origine jurídicos y que el juez puede directamente aplicar.

Hemos insistido sobre la complejidad jurídica, y justamente, porque está bien expresada en una diferenciación puesta en evidencia por nuestra carta constitucional: la que se da entre 'República' y 'Estado'. La República es realidad basada sobre valores fundamentales e inderogables, los valores que sostienen y orientan desde hace más de setenta años la comunidad multietnica y multilingiiistica del pueblo italiano, comunidad juridicamente compleja y articulada en una pluralidad de ordenamientos jurídicos originarios. El Estado es el ordenamiento jurídico 
central, llamado a producir leyes y a garantizar al ciudadano libertad y seguridad gracias al ejercicio democrático del propio aparato de poderes.

Este paisaje jurídicamente 'plural' no dejó de turbar y de asustar a muchos juristas italianos habituados a la simplicidad del viejo paisaje posilustrado reducido al Estado unitario y a sus leyes. Precisamente por esto el nuevo pluralismo ha tardado en arrancar y algunos, sobre todo en los años Cincuenta y Sesenta del siglo pasado, han intentado reducir nuestra Constitución a una nobilísima filosofía, una filosofía que necesitaba de un legislador estatal para su transformación en dimensión auténticamente jurídica. De esa manera se habría conservado un paisaje decrepito, para muchos tranquilizador.

Hoy, a setenta y dos años de su entrada en vigor, tengo la satisfacción de constatar que el pluralismo jurídico querido por la Constitución está convirtiéndose en una fuerza de nuestra República. Existen junto a la centralidad de la ley y del legislador una amplia pluralidad de fuentes. Junto al derecho legislado se impone cada vez más un derecho jurisprudencial, donde los actores son maestros teóricos y notarios, y sobre todo jueces. Los jueces, cada vez más conscientes de su papel activo, ejercen de motor de la dinámica de la experiencia jurídica. La brújula orientadora en la realidad italiana por tradición estatalista y legalista, más que el viejo principio de legalidad de los ilustrados es un amplio 'Rule of Law".

Data de recebimento: 11/12/2020

Data de aprovação: 19/12/2020 